\title{
INVENTARISASI JENIS TUMBUHAN PAKU (PTERIDOPHYTA) DI DESA PADANG PELASAN KABUPATEN SELUMA
}

Andika Pradipta ${ }^{1}$,Rara Saputri ${ }^{2}$, Seri Dewi Ami ${ }^{3}$, Ahmad Walid ${ }^{4}$

1,2,3,4 IAIN Bengkulu. Raden Fatah Street, Pagar Dewa, Bengkulu 33829, Indonesia

*Corresponding author, e-mail: andikabengkulu25@gmail.com

\section{ABS TRACT}

This study aims to determine the types of ferns found in Padang Pelasan Village, Seluma Regency, Bengkulu Province. The research was conducted using a qualitative descriptive method, namely research by collecting data or words. Sampling Pteridophyta was done by the Cruise Method. Data obtained from ferns (Pteridophyta) was then identified by observing samples consisting of roots, stems, leaves, and spores. The ferns found were brought to the nail cultivation site and the planting process was carried out. Based on the research results, the results of the inventory of ferns in Padang Pelasan Village, Seluma Regency, found 30 species of ferns consisting of 12 families, namely 3 species of Blechnaceae, 2 species of Selaginellaceae, 1 species of Dennstaedtiaceae, 1 species of Gleicheniaceae, 6 species of Pteridaceae. 1 species of Lygodiaceae, 4 species of Schizaceae, 1 species of Davalliaceae, 1 species of Athyriaceae, 1 species of Aspleniaceae, 7 species of Polypodiaceae, and 1 species of Equisetaceae. The most dominating ferns are the Polypodiaceae with 7 species.

Keywords: Inventory, Pteridophyta, Padang Pelasan

\section{PENDAHULUAN}

Indonesia merupakan Negara dengan tingkat kekhasan flora yang tinggi dan penyumbang keanekaragaman hayati dunia. Keanekaragaman tumbuhan tersebut meliputi tumbuhan berbiji yang terdiri dari Angiosperm dan Gymnosperm maupun tumbuhan berspora yang terdiri dari lumut dan paku-pakuan (Hanas dkk., 2019). Tumbuhan paku diklasifikasikan berdasarkan perbedaan morfologi tumbuhan dibagi menjadi 4 golongan, yaitu psilophyta (paku purba, paku ekor kuda, dan paku telanjang), Lycophyta (paku kawat, paku rambat), Equisetophyta Keanekaragaman jenis ini menunjukkan seluruh variasi yang terdapat pada makhluk hidup antar jenis (interspesies) dalam satu marga (Khamalia dkk., 2018).

Tumbuhan paku merupakan golongan tumbuhan yang menghasilkan spora namun sudah mempunyai berkas pengangkut, sehingga termasuk dalam tumbuhan vascular. Jumlah jenis tumbuhan paku cukup tinggi, yaitu 10.000 sampai 11.000 jenis yang tersebar diberbagai tipe habitat seperti terrestrial, aquatic dan epipet (Sopianti, dkk, 2020). Pertumbuhan dan perkembangan tumbuhan dipengaruhi oleh berbagai faktor-faktor yang dapat dibedakan menjadi dua, yaitu faktor dalam (internal) yaitu gen dan hormon. Sedangkan faktor luar (eksternal) yaitu air, mineral, cahaya matahari, suhu, dan kelembapan (Saktyowati, 2010).

Tumbuhan Paku (Pteridophyta) sebagai bagian dari keanekaragaman hayati merupakan komunitas tumbuhan yang memiliki fungsi ekologis yang cukup penting didalam ekosistem hutan, seperti sebagai vegetasi penutup tanah, pencampur serasah bagi pembentukan hara tanah, dan produsen dalam rantai makanan, disamping itu 
berperan sebagai sumber plasma nutfah juga berpotensi sebagai sumber pangan dan obat-obatan. Hal tersebut perlu mendapatkan perhatian yang cukup besar didalam pengelolaannya. Tumbuhan paku memiliki keanekaragaman jenis yang tinggi dan mampu hidup dalam kondisi lingkungan yang bervariasi. Keberadaan paku-pakuan ini masih kurang mendapat perhatian dibanding kelompok tumbuhan lainnya dan seringkali terabaikan (Suraida dkk., 2013).

Oleh karena itu, perlu perhatian yang serius untuk menyelesaikan dasar permasalahan penurunan keanekaragaman hayati dan mengetahui keanekaragaman hayati merupakan salah satu dasar upaya konservasi untuk mencegah terjadinya kepunahan agar jenisnya tetap terjaga pada saat ini dan masa yang akan datang. Jumlah dan jenis keanekaragaman hayati selalu berubah dari tahun ketahun, dari satu tempat dengan tempat lainnya berdasarkan beberapa fakta tersebut, maka sangat penting untuk mengetahui inventarisasi tumbuhan paku (Imaniar dkk., 2017).

Salah satu daerah yang banyak ditemukan tumbuhan paku adalah Desa Padang Pelasan di Kabupaten Seluma yang memiliki 14 Kecamatan, 20 Kelurahan, dan 182 Desa, luas wilayah Kabupaten Seluma mencapai $2.400,44 \mathrm{Km}^{2}$ dan memiliki penduduk 207.587 jiwa. Desa Padang Pelasan terletak di daerah Pegunungan yang memiliki tekstur tanah yang sangat lembab dengan tekstur tanah yang seperti ini membuat tumbuhan paku dapat tumbuh subur di daerah Desa Padang Pelasan. Selain itu, Pembukaan lahan untuk pembuatan jalan, ladang pertanian, dan perkebunan dapat menyebabkan berkurangnya jenis-jenis tumbuhan yang terdapat di kawasan tersebut (Betty dkk., 2015). Oleh karena itu, perlu dilakukan penelitian mengenai inventarisasi jenisjenis tumbuhan paku terestrial di daerah tersebut untuk menghindari ancaman kepunahan terhadap tumbuhan paku terestrial yang memungkinkan untuk dilestarikan dan dimanfaatan secara optimalPenelitian ini bertujuan untuk mengetahui jenis tumbuhan paku-pakuan (Pteridophyta) yang terdapat di Desa Padang Pelasan, Kab. Seluma Provinsi Bengkulu.

\section{METODE}

\section{Alat dan Bahan}

Alat yang digunakan dalam penelitian ini adalah Buku referensi tumbuhan paku (Pteridophyta), kamera, alat tulis, pisau, gunting, koran, karton, kertas label, isolasi, botol semprot, plastik, plastik bening, benang, jarum, air, peta lokasi, dan semua tumbuhan paku (Pteridophyta).

\section{Prosedur Penelitian}

Jenis penelitian yang dilakukan adalah penelitian deskriptif eksploratif. Penelitian ini dilakukan di Desa Padang Pelasan Kab.Seluma Provinsi Bengkulu. metode pengambilan sampel tumbuhan paku (Pteridophyta) dilakukan dengan cara jelajah (Cruise Method). Penelitian ini diawali dengan kegiatan observasi yang bertujuan untuk mendapatkan data awal mengenai tumbuhan paku yang ada di Desa Padang Pelasan Kabupaten Seluma. Selanjutnya melakukan pengamatan dan pengambilan sampel yang terdiri dari akar, batang, daun dan spora untuk dikoleksi. Kemudian dimasukkan kedalam kantong plastik putih berlabel yang berisi keterangan nomor spesies, nama lokal, lokasi dan nama tumbuhan paku (Pteridophyta) (Wahyuningsih dkk., 2019). Tumbuhan paku yag ditemukan dibawa ke tempat budi daya paku dan selanjutnya dilakukan proses penanaman, kemudian diidentifikasi berdasarkan ciri-ciri yang dimiliki. 


\section{Analisis Data}

Data yang dikumpulkan dianalisis secara deskriptif. Tumbuhan paku yang diperoleh dari jenis tumbuhan paku (Pteridophyta) lalu diidentifikasi dengan mengacu pada buku panduan Steenis (2013), Fitriana (2008), Saktyowati (2016), Mardiastutik (2013), Tjitrosomo (2010) dan Wijaya (2014).

\section{HASIL DAN PEMBAHASAN}

Penelitian yang dilakukan di Desa Padang Pelasan Kab.Seluma Provinsi Bengkulu pada tanggal 20-26 April 2020, hasil inventarisasi tumbuhan paku di Desa Padang Pelasan Kab.Seluma di temukan 30 spesies tumbuhan paku yang tergolong dari 12 famili (Tabel 1).

Tabel 1. Jenis Tumbuhan Paku yang ditemukan di Desa Padang Pelasan Kab. Seluma Prov. Bengkulu.

\begin{tabular}{|c|c|}
\hline Famili & Spesies \\
\hline \multirow[t]{3}{*}{ Blechnaceae } & Stenochlaena palusteris \\
\hline & Stenochlaena milnei \\
\hline & Blechnum occidental \\
\hline \multirow[t]{2}{*}{ Selaginellaceae } & Selaginella wildennowi \\
\hline & Selaginella biformis \\
\hline Dennstaedtiaceae & Pteridium aqualinum \\
\hline Gleicheniaceae & Gleichenia linearis \\
\hline \multirow[t]{6}{*}{ Pteridaceae } & Pteris longifolia \\
\hline & Pteris ensiformis \\
\hline & Adiantum peruvianum \\
\hline & Adiantum raddianum \\
\hline & Adiantum tenerum \\
\hline & Pityrogmma calomelanos \\
\hline Lygodiaceae & Lygodium palmatum \\
\hline \multirow[t]{4}{*}{ Schizaceae } & Lygodium flexuosum \\
\hline & Lygodium microhyllum \\
\hline & Lygodium longifolium \\
\hline & Lygodium circinnatum \\
\hline Davalliaceae & Davalia solida \\
\hline Athyriaceae & Diplazium esculentum \\
\hline Aspleniaceae & Asplenium nidus \\
\hline \multirow[t]{7}{*}{ Polypodiaceae } & Pyrrosia piloselloides \\
\hline & Pyrrosia namularifolia \\
\hline & Drynaria quercifolia \\
\hline & Microsorum pteropus \\
\hline & Phelebodium aureum \\
\hline & Platycerium bifurcantum \\
\hline & Nephrolepis biserrata \\
\hline Equisetaceae & Equesetum hyemale \\
\hline
\end{tabular}

Famili tumbuhan paku yang ditemukan yaitu, Blechnaceae, Sellaginellaceae, Dennstaedtiaceae, Davalliaceae, Gleicheniaceae, Lygodiaceae, Polypodiaceae, Pteridaceae, Schizaceae, Athyriaceeae, Nephrolepidaceae, Aspleniaceae dan Equisetaceae, dengan 30 spesies tumbuhan paku (Pteridophyta). Dari hasil yang diperoleh diketahui bahwa jenis paku yang banyak ditemukan di Desa Padang Pelasan Kabupaten Seluma Provinsi Bengkulu yaitu jenis paku dengan famili Polypodiceae sebanyak 7 spesies yaitu Pyrrosia piloselloides, Pyrrosia namularifolia, Drynaria quercifolia, Microsorum pteropus, Phelebodium aureum, Nephrolepis biserrata dan Platycerium bifurcantum. Jenis paku-pakuan ini banyak terdapat di 
daerah Padang Pelasan karena daerah tersebut masih terdapat banyak hutan-hutan yang asri sehingga menjadikan kondisi tanah lembab.

Menurut Mardiyah dkk (2017), Keadaan hutan yang memiliki tingkat kelembapan yang tinggi, menjadikan keanekaragaman hayati dari jenis tumbuhan paku. Tumbuhan paku tergolong kelompok tumbuhan dengan sistem pembuluh sejati (Tracheophyta, memiliki pembuluh kayu dan pembuluh tapis) tetapi tidak menghasilkan biji untuk reproduksi seksualnya kelompok tumbuhan ini mempertahankan spora sebagai alat perbanyakan generatifnya maka tumbuhan paku dapat ditemukan di sekitar Padang Pelasan.

Famili Polypodiceae memiliki ciri yaitu habitat teresterial, memiliki ciri daun tunggal dan tersusun pada batang yang sangat pendek, tepi daun bergerigi besar berwarna hijau muda, akar berbulu dengan warna coklat tua. Sorus tersebar merata pada permukaan bagian bawah daun berwarna coklat kemerahan (Taslim dkk., 2019). Menurut Permana (2017), tumbuhan paku (Pteridophyta) memiliki tingkat toleransi tertentu terhadap kondisi lingkungannya agar tetap hidup dan berkembang. Jika kondisi lingkungan berubah melebihi tingkat toleransinya, maka akan mengakibatkan kemusnahan tumbuhan dari habitat tersebut. Hal ini sesuai hasil penelitian Wahyuningsih dkk (2019), yang menjelaskan bahwa jenis-jenis tumbuhan paku yang hanya dapat ditemukan pada area tertentu karena memiliki daya toleransi yang rendah terhadap kondisi lingkungan. Selain itu, faktor lingkungan seperti kelembapan yang tinggi, aliran air yang banyak, adanya kabut dan curah hujan yang tinggi sangat mempengaruhi jumlah tumbuhan yang tumbuh (Astuti dkk, 2017). Pendapat lain dikemukan oleh Marpaung, dkk (2019), Banyaknya jenis dari famili Polypodiaceae pada lokasi disebabkan kondisi faktor fisik yang sesuai bagi perkembangan dan keberlangsungan hidup jenis tumbuhan paku tersebut.

Famili dengan jumlah spesies terbanyak adalah Famili Pteridaceae yang terdiri dari 6 spesies yaitu Pteris longifolia, Pteris ensiformis, Adiantum peruvianum, Adiantum raddianum, Adiantum tenerum dan Pityrogmma calomelanos. Jenis famili ini merupakan paku terestrial yang tumbuh di tanah dan batu-batu. Tinggi mencapai $150 \mathrm{~cm}$. Daun majemuk memiliki panjang hingga $50 \mathrm{~cm}$ dan lebar $3 \mathrm{~cm}$. Batang berwarna hitam dan beralur. Sorus berada di tepi daun dan tersusun beraturan. Beberapa jenis dari marga Pteris banyak dimanfaatkan sebagai sayuran terutama daun muda (Arini \& Kinho, 2012).

Famili Schizaceae yang dijumpai di Desa Padang Pelasan terdiri atas 4 spesies yaitu Lygodium flexuosum, Lygodium microhyllum, Lygodium longifolium dan Lygodium circinnatum. Famili ini cenderung memiliki habitat terestrial, batang (caulis) permukaan batang bulat dan licin serta arah tumbuh batang membelit (volubilis) menggunakan penunjang dengan tumbuhan lain (Taslim dkk., 2019). Sedangkan menurut (Steenis, 2013), paku ini memiliki akar rimpang merayap, batang naik atau tegak. Daun naik atau membelit ke kiri, kadang-kadang tunggal dan menggarpu dan menggarpu tepi rata, kadang-kadang menyirip. Sporangia dalam 2 atau 4 garis pada bagian bawah dari tajuk daun yang sempit berbentuk garis, diujung dengan selaput penutup yang melintang, berbentuk tutup, berbentuk cincin sempurna atau telanjang.

Famili selanjutnya adalah Blechnaceae yang ditemukan 3 spesies yaitu Stenochlaena palusteris, Stenochlaena milnei, dan Blechnum occidental. Keunikan jenis paku ini adalah pada warna daunnya, pada saat kuncup daun tertutup oleh sorus berwarna coklat, pada waktu muda, daun yang berwarna terbuka berwarna merah 
dan lama kelamaan akan berubah berwarna hijau. Termasuk dalam jenis paku terestrial yang hidup pada suhu yang sangat rendah.

Famili Selaginellaceae ditemukan sebanyak 2 spesies yaitu, Selaginella wildennowi dan Selaginella biformis. Menurut Steenis (2013), Paku tanah, sangat jarang epifit. Daun kecil, tunggal, pada cabang samping terdiri dari daun besar yang kerapkali mudah rontok, 2 baris terdepan daun kecil yang duduknya menempel. Sporangia didalam ketiak daun yang fertil (sporofil) berdiri sendiri, beruang satu, berkatup dua, dua macam, berturut-turut dengan 1-4 spora besar atau spora kecil. Sporofil lebih besar dari pada sporangia, terkumpul menjadi bulir terminal, persegi empat, kadang-kadang agak pipih.

Famili yang hanya ditemukan satu spesies berjumlah 8 famili yaitu famili Dennstaedtiaceae, Gleicheniaceae, Lygodiaceae, Davalliaceae, Athyriaceae, Nephrolepidaceae, Aspleniaceae dan Equisetaceae. Menurut (Hanas dkk., 2019), Pteridium aqualinum termasuk famili Dennstaedtiaceae yang memiliki ciri-ciri yaitu habitat teresterial. Batang berupa rimpang, bercabang, menjalar panjang di bawah tanah. Daun majemuk besar; tangkai daun melekat pada rimpang di bawah tanah. Spora menutupi garis-garis pada bagian bawah daun. Sporangium diagregasi menjadi sori di bagian bawah daun.

Famili Gleicheniaceae merupakan Paku tanah. Akar merimpang merayap. Daun menyirip bercangap, menyirip atau menggarpu. Urat tulang daun bebas. Sori pada sisi bawah daun, telanjang, biasanya berbentuk bulat, terdiri dari 2-12 sporangia yang duduk atau sporangia yang betangkai, sporangia dengan cicin yang sempurna horizontal, membuka membujur (Steeniss, 2013). Spesies yang ditemukan adalah Gleichenia linearis. Menurut Hasibuan dkk (2016), Paku ini hidup secara terestrial di tempat terbuka. Banyak terdapat di daerah tepi sungai dan jurang dan tebing-tebing di tepi jalan di pegunungan. Tumbuhan ini mudah dikenal karena peletakan daunnya yang menyirip berjajar dua dan tangkainya bercabang mendua (dikotom), dapat pula memanjat dan menggantung. Pendapat lain dikemukan oleh Elsifa dkk (2019), Gleichenia linearis mempunyai percabangan khusus yaitu tiap-tiap cabang bercabang dua dan masing-masing cabang akan bercabang dua lagi. Akar berwarna hijau dan sporangium terdapat pada setiap Pina (anak daun) dan penyebarannya terbatas disepanjang daun.

Famili Lygodiaceae memiliki ciri-ciri hidup di daerah terestrial, pantropis. Karakter: rimpang merayap, langsing, protostelik, membawa rambut; Daun-daun tak tentu, memanjat, bergantian menyirip; divisi bilah utama (pinnae) pseudodichotomously forking dengan tunas aktif di axils; vena bebas atau anastomosing; sori pada lobus dari segmen tertinggi; sporangia abaxial, soliter, satu per sorus, masing-masing sporangium yang ditutupi oleh subtrat seperti indusium antrorse flens; spora 128-256 per sporangium, tetrahedral dan trilete; gametofit hijau, berseri-seri. Spesies yang ditemukan pada famili ini adalah Lygodium palmatum.

Famili Davalliaceae merupakan famili yang memiliki rimpang yang tahan kering dan menjalar kemana-mana serta menyenangi tempat terbuka sehingga mempunyai persebaran yang cukup luas. Spesies yang ditemukan pada famili ini adalah Davalia solida. Ciri dari spesies ini adalah hidup epifit, lamina berwarna hijau muda, dapat beradaptasi dengan keadaan sekitar dan dapat tumbuh dialam dengan cara beragam, misalnya menempel di batang pohon, batu, atau tumbuh di tanah. Selain itu, spesies ini lebih banyak ditemukan di perkebunan masyarakat, hutan 
sekunder dan jarang ditemukan pada hutan yang canopinya tertutup (Mildawati dkk, 2010).

Famili Athyriaceae hanya ditemukan 1 speseies yaitu Diplazium esculentum. Paku ini memiliki ciri-ciri yaitu akar serabut, batang tumbuh tegak berwarna hijau, memiliki permukaan licin terdapat sisik, tinggi sekitar 90-130cm, Anak daunnya bundar tumpul dengan tulang daun yang membentuk lekukan. Anak daun yang terujung mempunyai ujung yang lancip, daun berwarna hijau. sorus terdapat dibagian bawah daun, dimanfaatkan sebagai sayuran, dapat digunakan sebagai obat menurunkan panas badan, dapat juga digunakan sebagai obat setelah bersalin (Steenis, 2013).

Famili Aspleniaceae ditemukan hanya satu spesies yaitu Asplenium nidus dari famili Aspleniaceaae. Paku ini mudah dikenal karena tajuknya yang besar, menyerupai daun pisang, peruratan daun menyirip tunggal dan menyukai daerah yang agak lembab dan tahan terhadap sinar matahari langsung. Warna helai daun hijau cerah, dan menguning bila terkena cahaya matahari langsung. Ental-ental yang mengering akan membentuk semacam sarang burung yang menumpang pada cabang-cabang pohon (Hasibuan dkk, 2016)

Famili Equisetaceae adalah tumbuhan berumur panjang. Akar rimpang dibawah tanah, merayap. Batang berbuku, silindris, berusuk atau bergari membujur. Daun berkarangan, kecil, daun dari tiap karangan melekat hingga menjadi suatu saluran yang membujur, pada ujung satu upih yang bergigi, sporangia pada sisi bawah sisik berbentuk perisai dan tersusun karangan, sporangia menjadi bulir diujung, higroskopis, dalam keadaan lembab tergulung dan pada keadaan mengering menjadi lurus. Contohnya Equesetum hyemale, herba tegak atau berusaha tegak, atau juga pada pangkal merayap (Steenis, 2013).

Jenis tumbuhan paku yang ditemukan di Desa Padang Pelasan Kabupaten Seluma Provinsi Bengkulu ternyata memiliki banyak manfaat bagi manusia, baik sebagai tanaman hias, obat-obatan ataupun keperluan lain. Tumbuhan paku pada umumnya dimanfaatkan sebagai keperluan bahan makanan yang dijadikan sebagai sayur, pengobatan seperti (Gleichenia linearis) paku resam. Serta untuk bahan baku kerajinan tangan seperti pembuatan perangkap ikan serta keranjang.

\section{SIMPULAN}

Berdasarkan hasil penelitian inventarisasi tumbuhan paku di Desa Padang Pelasan Kab. Seluma, Provinsi Bengkulu ditemukan 30 spesies tumbuhan paku yang tergolong dari 12 famili dan didominasi oleh famili Polypodiceae.

\section{REFERENSI}

Arini, D.I.D., \& Kinho, J. (2012). Keragaman Jenis Tumbuhan Paku (Pteridophyta) Di Cagar Alam Gunung Ambang Sulawesi Utara (The Pteridhopyta Diversity In Gunung Ambang Nature Reserve North Sulawesi). Jurnal BPK Manado, 2(1), 24-37.

Astuti, F.K, Murningsih \& Jumari. (2018). Keanekaragaman Jenis Tumbuhan Paku Pteridophyta Jalur Pendakian Selo Kawasan Taman Nasional Gunung Merbabu Jawa Tengah. Jurnal Bioma, 20(1), 25-30

Betty, J., Linda, R \& Lovandi, I. (2015). Inventarisasi Jenis Paku-Pakuan (Pteridophyta) Terrestrial Di Hutan Dusun Tauk Kecamatan Air Besar Kabupaten Landak. Protobiont, 4(1), 94-102 
Elsifa, A., Arisandy, A.D \& Harmoko. (2019). Eksplorasi Tumbuhan Paku (Pteridophyta) Di STL Ulu Terawas, Musi Rawas, Sumatera Selatan. BIOSFER: Jurnal Tadris Biologi, 10(1), 47-55.

Fitriana, R. (2008). Mengenal Tumbuhan. Bandung: Putra Setia.

Hanas D, F., Bria E. J \& Y Tnunay I.M.Y. (2019). Inventarisasi Tumbuhan Paku (Pteridophyta) Di Oelmuke Desa Tasinifu Kecamatan Mutis Kabupaten Timor Tengah Utara. Jurnal Saintek Lahan Kering, 2(2), 30-32.

Hasibuan H, Rizalinda \& Rusmianto P.W. (2016). Inventarisasi Jenis Paku-Pakuan Pteridophyta Di Hutan Sebelah Darat Kecamatan Sungai Ambawang Kalimantan Barat. Protobiont. 5(1), 46-58.

Imaniar, R., Pujiastuti \& Murdyah S. (2017). Identifikasi Keanekaragaman Tumbuhan Paku Dikawasan Air Terjun Kapas Biru Kecamatan Pronojiwo Kabupaten Lumanjang Serta Pemanfaatannya Sebagai Booklet. Jurnal Pendidikan Biologi, 6(3), 337-345.

Khamalia Imalia, Herawatiningsih R \& Ardian H. (2018). Keanekaragaman Jenis PakuPakuan Di Kawasan UIPHHK-HTI PT.Bahtara Alam Lestari Kabupaten Mempawah. Jurnal Hutan Lestari, 6(3), 510-518.

Mardiastutik, W. (2013). Mengenal Tumbuhan. Bekasi: Mitra Utama

Mardiyah A, Hasanudin \& Eriawati. (2017). Inventarisasi Jenis Paku Di Kawasan Gunung Paroy Kecamatan Lhong Kabupaten Aceh Besar. Prosiding Seminar Nasional Biotik. Aceh: Program Studi Pendidikan Biologi Fakultas Tarbiyah dan Kependidikan Universitas Islam Negeri Ar-Raniry

Marpaung, D.R.A.K (2019). Inventarisasi Tumbuhan Paku (Pteridophyta) Di Sopotinjak Taman Nasional Batang Gadis (TNBG) Kabupaten Mandailing Natal. Jurnal Penelitian dan Pembelajaran MIPA ,4(2), 79-84.

Mildawati, Arbain A., \&Y Syamsuardi. (2010). Diversitas Davallia di Sumatera Barat. Jurnal Prosiding Seminar dan Rapat Tahunan BKS-PTN Wilayah Barat Ke-21. Fakultas MIPA, Universitas Bengkulu.

Permana, N, E, P. (2017). Identifikasi keanekaragaman Divisi Pteridophyta (Paku) di kawasan Bukit Sulap Kota Lubuklinggau. Skripsi. Lubuklinggau: STKIP PGRI Lubuklinggau.

Saktyowati, D. (2010). Mengenal Dunia Tumbuhan. Jakarta: Multazam Mulia Utama.

Sopianti, N., Atika Afni M, Suriatno R \& Pranata S. (2020). Jenis-Jenis Tumbuhan Paku Di Pulau Rangsang, Kepulauan Meranti, Riau dan Karakteristik Morfologi Palinologi. Jurnal Biologi Tropis, 20(1), 102-110

Steenis, C.G.G.J.Van. (2013). Flora. Jakarta Timur: Balai Pustaka.

Suraida, Susanti T \& Amrianto R. (2013). Keanekaragaman Tumbuhan Paku (Pteridophyta) Di Taman Hutan Kenali Kota Jambi. Jurnal Prosiding Semirata FMIPA Lampung.

Taslim E, Ramadanil \& M Sulaeman S. (2019). Inventarisasi Jenis Paku-Pakuan (Pteridophyta) di Jalur Pendakian Nokilalaki Kawasan Taman Nasional Lore Lindu. Biocelebes. 13 (2), 152-161

Tjitrosomo, S.S. (2010). Botani Umum 3. Bandung: Angkasa.

Wahyuningsih, Triyanti M, \& Serprianingsih. (2019). Inventarisasi Tumbuhan Paku (Pteridophyta) Di Perkebunan PT BINA SAINS CEMERLANG Kabupaten Musi $\begin{array}{llll}\text { Rawas. Jurnal } & \text { Biosilampari, } & 2 & \text { (1), }\end{array}$ https://doi.org/10.31540/biosilampari.v2i1.815

Wijaya, N. (2014). Biologi \& Lingkungan. Yogyakarta:Plantaxia. 